\title{
Repair of anomalous origin of the left coronary artery from the pulmonary artery in infants and children
}

\author{
Vladimir Alexi-Meskishvili, MD, PhD, ${ }^{\mathrm{a}}$ Boris A. Nasseri, MD, ${ }^{\mathrm{a}}$ Sarah Nordmeyer, MD, \\ Boris Schmitt, MD, ${ }^{\mathrm{b}}$ Yu-Guo Weng, MD, ${ }^{\mathrm{a}}$ Wolfgang Böttcher, ECCP, ${ }^{\mathrm{a}}$ Michael Hübler, MD, ${ }^{\mathrm{a}}$ \\ Felix Berger, $\mathrm{MD}, \mathrm{PhD},{ }^{\mathrm{c}}$ and Roland Hetzer, $\mathrm{MD}, \mathrm{PhD}^{\mathrm{a}}$
}

\begin{abstract}
Objective: Although mortality after direct aortic reimplantation for anomalous origin of the left coronary artery from the pulmonary artery (ALCAPA) has significantly decreased, many questions remain unanswered.

Methods: Between 1986 and June 2010, we operated on 27 consecutive pediatric patients with anomalous origin of the left coronary artery from the pulmonary artery (ALCAPA). All patients underwent reestablishment of a dual coronary system with direct aortic reimplantation of the left coronary artery into the aorta. Postoperative extracorporeal mechanical circulatory support was necessary in 7 cases. In all 7 patients, hemodynamic stability was achieved after 4 to 10 days of support. Mitral valve repair was performed in 9 patients with severe mitral valve incompetence and resulted in stable mitral valve function during follow-up as long as 19 years.
\end{abstract}

\begin{abstract}
Results: There were no early or late deaths. During follow-up (3 months-17.5 years), both early and late improvement of myocardial function was observed in all patients. Reduced left ventricular regional function late after successful surgical correction of ALCAPA was related to the presence of left ventricular myocardial scar tissue, as detected by magnetic resonance imaging.

Conclusions: Despite the absence of early and late mortality, the long-term prognosis for patients after reimplantation of ALCAPA into the aorta is not clear. Scars and perfusion deficits of the left ventricle may not be detected by standard echocardiographic evaluation of global left ventricular function and therefore may be underestimated. We therefore recommend lifelong surveillance of these patients, including magnetic resonance imaging. (J Thorac Cardiovasc Surg 2011;142:868-74)
\end{abstract}

Anomalous origin of the left coronary artery from the pulmonary artery (ALCAPA) is a rare congenital heart defect with very high natural mortality during infancy. ${ }^{1,2}$ These days, establishment of a dual coronary system with reimplantation of the left coronary artery into the aorta is the preferred method for treatment of ALCAPA. ${ }^{3}$ Mortality has significantly decreased in recent years, approaching nilin some recent reports. ${ }^{4,5}$

Despite low mortality in published reports, many questions remain unanswered:

- Will left ventricular function completely recover?

- Will the ischemic mitral valve incompetence (MVI) regress or disappear without mitral valve surgery during reimplantation?

- Will there be a satisfactory patency rate of the coronary artery reimplanted into the aorta?

\footnotetext{
From the Departments of Cardiothoracic and Vascular Surgery, ${ }^{\mathrm{a}}$ Pediatric Cardiology, and Congenital Heart Diseases, ${ }^{\mathrm{c}}$ Deutsches Herzzentrum Berlin, Berlin, Germany. Disclosures: Authors have nothing to disclose with regard to commercial support.

V.A.-M. and B.A.N. contributed equally to this work.

Received for publication Dec 28, 2010; revisions received March 22, 2011; accepted for publication April 8, 2011; available ahead of print June 13, 2011.

Address for reprints: Vladimir Alexi-Meskishvili, MD, PhD, Department of Cardiothoracic and Vascular Surgery, Deutsches Herzzentrum Berlin, Augustenburger Platz 1, 13353 Berlin, Germany (E-mail: alexi@dhzb.de).

0022-5223/\$36.00

Copyright (c) 2011 by The American Association for Thoracic Surgery doi:10.1016/j.jtcvs.2011.04.006
}

- Is direct coronary transfer possible in all cases?

- Is the use of postoperative mechanical circulatory support predictable or even avoidable?

We report our experience with direct reimplantation of the left coronary artery into the aorta in 27 consecutive pediatric patients operated on between January 1992 and June 2010 in the Deutsches Herzzentrum Berlin.

\section{MATERIALS AND METHODS \\ Patients}

Permission to review the health records and follow-up was obtained from the institutional review board committee. The need for individual or parental consent was waived.

The study population consisted of all 27 pediatric patients with ALCAPA seen at our institution since the inception of the pediatric cardiac program in May 1986 (Table 1). In all 27 cases, direct reimplantation of the left coronary artery into the aorta was performed. Thirteen of these patients have been reported on elsewhere. ${ }^{6-8}$ Median age of the 27 patients was 0.8 years (range, $0.1-10.8$ years) and median body weight was $8 \mathrm{~kg}$ (range, $3.6-38 \mathrm{~kg}$ ). There were 14 girls and 13 boys. Fifteen patients were infants, 4 boys and 11 girls with median age of 3.7 months (range, 1.012 months). Nine infants were younger than 6 months, and 4 were younger than 3 months. The median body weight of the infants was $5.5 \mathrm{~kg}$ (range, 3.6-8.3 kg). Two infants were transferred to our hospital to be evaluated for heart transplant. All infants underwent emergency operation because of symptoms of severe left ventricular dysfunction and congestive heart failure. Six of these infants were intubated and mechanically ventilated for 1 to 6 days before operation because of cardiopulmonary instability,with resuscitation in 2 of these cases. All older children ( $>1$ year of age) underwent elective operation. 


\section{Abbreviations and Acronyms \\ ALCAPA $=$ anomalous origin of the left coronary artery from the pulmonary artery \\ LVAD $=$ left ventricular assist device \\ LVEDD $=$ left ventricular end-diastolic diameter \\ LVEF = left ventricular ejection fraction \\ LVFS = left ventricular fraction of shortening \\ MRI = magnetic resonance imaging \\ MVI = mitral valve incompetence}

\section{Surgical Technique}

Surgery for all patients was performed through a median sternotomy and included bicaval cannulation and cardiopulmonary bypass with moderate hypothermia (rectal temperature $20^{\circ} \mathrm{C}$ to $30^{\circ} \mathrm{C}$ ). After clamping of the aorta and snaring of the right and left pulmonary arteries, cold crystalloid cardioplegic solution (10 mL/kg; Dr Franz Köhler Chemie GmbH, Albach, Germany) and then hydroxyl starch cardioplegic solution ( $15 \mathrm{ml} / \mathrm{kg}$; Fresenius AG, Homburg, Germany) was simultaneously injected into the aortic root and the main pulmonary artery, as described elsewhere. ${ }^{6}$

The pulmonary sinuses were designated right (sinus 1), left (sinus 2), or nonfacing, according to the view from the nonfacing sinus looking toward the aorta. ${ }^{9,10}$ The left coronary artery originated from the right-facing sinus in 19 patients, from the left-facing sinus in 2 patients, from the nonfacing sinus in 4, patients, and from the pulmonary bifurcation and right pulmonary artery in 1 case each.

The surgical technique has been reported in detail elsewhere and has not changed since that publication. ${ }^{6}$ In all cases, coronary transfer to the ascending aorta was performed. To obtain tension-free anastomosis, the left coronary artery was dissected up to the origin of the circumflex coronary artery. Because extra length was required to ensure tension-free communication with the ascending aorta in 1 infant in whom the left coronary artery originated from the nonfacing pulmonary sinus (patient 11; Table 1), a pulmonary artery flap, constructed according to a technique described by Stiles and others, ${ }^{6,11}$ was used. After left coronary artery reimplantation was performed, the pulmonary sinus of Valsalva, which previously had hosted the coronary ostium or, respectively, the pulmonary bifurcation or right pulmonary artery was reconstructed with autologous native pericardium. Once reconstruction was completed, the continuity of the previously divided pulmonary trunk was reestablished through direct anastomosis with continuous absorbable monofilament sutures.

Additionally, 9 patients ( 3 of them infants) with grade III or IV MVI underwent a modified Kay-Wooler (5 patients) or Paneth (4 patients) mitral annuloplasty, combined with giant left atrium plication in 1 case and with shortening of elongated chordae in 2 cases.

Aortic cross clamp time ranged from 22 to 106 minutes (median, 57 minutes). Median aortic clamp time was 66 minutes (range, 35-106 minutes) in patients with mitral valve repair and 55 minutes (range, 2279 minutes) in patients without mitral valve repair. Additional procedures were performed in 3 patients: division of a patent ductus arteriosus in 2 cases and patch closure of a ventricular septal defect in 1 case.

After the operation, the chest was left open in 14 patients: in 2 cases because of severe ventricular arrhythmia, in 5 cases because of hemodynamic instability that developed after temporary sternal closure, and in 7 cases because of the necessity of temporary mechanical circulatory support (left ventricular assist device [LVAD] in 6 infants and extracorporeal membrane oxygenation in 1 older patient; Table 1). One patient had severe low cardiac output while in the intensive care unit. He underwent rethoracotomy, and the chest was left open. Six infants needed support with LVADs because attempts at weaning from cardiopulmonary bypass were unsuccessful despite prolonged reperfusion (180-330 minutes) and maximal inotropic support. Left ventricular support was performed with centrifugal pumps (BP-50, Bio-Pump; Bio-Medicus, Medtronic Inc, Eden Prairie, Minn) in 4 infants and lasted for 5 to 9 days. ${ }^{7}$ Left ventricular function was virtually absent in 2 infants, and functional recovery was not anticipated within a period of 4 to 7 days, in which we would usually perform circulatory support with a centrifugal pump. Therefore a Berlin Heart Excor pneumatic VAD (Berlin Heart AG, Berlin, Germany) was implanted in these 2 patients. ${ }^{8,12}$ Selective coronary angiography during support with Berlin Heart VAD revealed an open, unobstructed coronary anastomosis.

One preoperatively symptom-free 9 -year-old boy showed severe right ventricular failure after left coronary artery reimplantation and could not be weaned from cardiopulmonary bypass. An extracorporeal membrane oxygenator was implanted, and the patient was supported for 5 days. The child was extubated on the 9th postoperative day. Retrospectively, this patient was found to have severe supravalvular iatrogenic pulmonary stenosis, which was not recognized at the time. One year after coronary reimplantation, pulmonary arterioplasty and infundibulectomy were performed. The patient is now 23 years old and free of symptoms.

\section{Statistics}

SPSS for Windows version 12.01 (SPSS Inc, an IBM Company, Chicago, Ill) was used for statistical analysis. Qualitative data are presented as numbers and percentages, and quantitative data were presented as medians and ranges. Patient groups were compared by means of the Wilcoxon rank sum test.

\section{RESULTS}

The electrocardiogram in 14 infants and 5 older children showed myocardial infarction patterns $(\mathrm{Q}$ waves in leads I and aVl). Cardiomegaly (cardiothoracic ratio, $>0.5$ ) was observed in 24 patients (mean cardiothoracic ratio, $0.65 \pm$ 0.06). In 3 older children, the cardiothoracic ratio was 0.35 to 0.5 .

All patients underwent preoperative cardiac catheterization. Left ventricular end-diastolic pressure was a median of $15 \mathrm{~mm} \mathrm{Hg}$ (range, 5-25 $\mathrm{mm} \mathrm{Hg}$ ) and was higher than $11 \mathrm{~mm} \mathrm{Hg}$ in 16 of the patients (Table 1). Sixteen patients had insufficient collaterals between the right and left coronary arteries. No patient had significantly elevated pulmonary arterial pressure.

Echocardiographic examination, which included determination of left ventricular end-diastolic diameter (LVEDD), left ventricular ejection fraction (LVEF), and left ventricular fraction of shortening (LVFS), was performed in all patients before operation. LVEF was severely impaired $(\leq 30 \%)$ in 7 patients, impaired $(31 \%-40 \%)$ in 5 , mildly impaired $(41 \%-$ $50 \%)$ in 5 , and normal $(\geq 51 \%)$ in 10 . LVFS was $20 \%$ or lower in 14 patients. Preoperative mean zscore LVEDD (LVEDD corrected for body surface area) was significantly higher (7.1; range, 0.6-18.5; vs 3.3; range, 0-4.9; $P=.003$ ), and LVEF and LVFS were significantly lower in infants than in older children $(37 \%$; range, $19 \%-76 \%$; vs $56 \%$; range, $29 \%-75 \%$; $P=.006$; and $18 \%$; range, $7 \%$ $30 \%$; vs $28 \%$; range, $15 \%-45 \%$; $P=.001$, respectively).

MVI was evaluated according to Buck and co-authors. ${ }^{13}$ MVI was absent (grade 0) in 7 patients, mild (grade I) in 4, 
TABLE 1. Patient data

\begin{tabular}{|c|c|c|c|c|c|c|c|c|c|c|c|c|c|c|c|c|c|}
\hline Case & $\begin{array}{c}\begin{array}{c}\text { Year of } \\
\text { operation }\end{array} \\
\end{array}$ & $\begin{array}{l}\text { Age } \\
(\mathbf{y})\end{array}$ & Sex & $\begin{array}{c}\text { Weight } \\
(\mathrm{kg})\end{array}$ & $\begin{array}{c}\text { LCA } \\
\text { origin }\end{array}$ & $\begin{array}{c}\text { Preop } \\
\text { MVI }\end{array}$ & $\begin{array}{c}\text { LVEDP } \\
(\mathrm{mm} \mathrm{Hg})\end{array}$ & $\begin{array}{c}\text { LVEDD } \\
z \text { score }\end{array}$ & $\begin{array}{c}\text { LVEDD } \\
(\mathbf{c m})\end{array}$ & $\begin{array}{c}\text { LVEF } \\
(\%)\end{array}$ & $\begin{array}{c}\text { LVFS } \\
(\%)\end{array}$ & $\begin{array}{c}\text { Aortic } \\
\text { clamp } \\
\text { time }(\mathbf{m i n})\end{array}$ & $\begin{array}{c}\text { Reperfusion } \\
\text { (min) }\end{array}$ & $\begin{array}{c}\text { LVAD } \\
\text { duration } \\
\text { (d) }\end{array}$ & $\begin{array}{c}\text { DSC } \\
\text { (d) }\end{array}$ & $\begin{array}{c}\text { Follow-up } \\
\text { at DHZB } \\
(y) \\
\end{array}$ & $\begin{array}{c}\text { Late } \\
\text { postop } \\
\text { MVI } \\
\end{array}$ \\
\hline 1 & 1992 & 0.3 & F & 5.7 & RFS & 0 & 7 & 5.1 & 3.2 & 42 & 20 & 22 & 55 & - & 4 & 17.5 & 1 \\
\hline 2 & 1992 & 10.5 & M & 29.5 & RFS & 2 & 16 & 2.5 & 4.7 & 29 & 25 & 54 & 40 & - & - & 15.7 & 1 \\
\hline 3 & 1992 & 3.0 & $\mathrm{~F}$ & 12.9 & RFS & 3 & 16 & 1.9 & 3.6 & 56 & 29 & 35 & 50 & - & - & 16.0 & $1^{*}$ \\
\hline 4 & 1992 & 0.6 & F & 5.3 & RFS & 4 & 20 & 10.6 & 3.8 & 35 & 27 & 78 & 50 & - & 4 & $\mathrm{NF}$ & $1^{*}$ \\
\hline 5 & 1992 & 2.8 & $\mathrm{~F}$ & 13.5 & RFS & 3 & 10 & 6.6 & 5 & 30 & 15 & 57 & 40 & - & 1 & $\mathrm{NF}$ & $1^{*}$ \\
\hline 6 & 1992 & 0.2 & $\mathrm{M}$ & 5.3 & MPA & 0 & 18 & 5.6 & 3.3 & 23 & 13 & 57 & 36 & - & 3 & 16.3 & 1 \\
\hline 7 & 1992 & 0.3 & $\mathrm{~F}$ & 4 & RFS & 1 & 20 & 5.9 & 3 & 56 & 26 & 53 & 45 & - & 4 & 15.8 & 1 \\
\hline 8 & 1993 & 0.3 & $\mathrm{~F}$ & 4 & NFS & 3 & 9 & 0.6 & 2.1 & 38 & 22 & 34 & 60 & - & 3 & 15.7 & 1 \\
\hline 9 & 1993 & 8.2 & $\mathrm{M}$ & 20 & NFS & 0 & 5 & 0 & 3.6 & 70 & 33 & 77 & 270 & $6 \dagger$ & 5 & 14.6 & 0 \\
\hline 10 & 1993 & 5.1 & $\mathrm{M}$ & 20 & RFS & 0 & 12 & 4 & 4.7 & 56 & 27 & 55 & 48 & - & - & 15.8 & 2 \\
\hline 11 & 1993 & 0.8 & $\mathrm{~F}$ & 5.7 & NFS & 0 & 20 & 18.5 & 6 & 37 & 15 & 79 & 251 & $9 \ddagger$ & 10 & 15.2 & 1 \\
\hline 12 & 1993 & 5.9 & $\mathrm{M}$ & 25 & RFS & 0 & 7 & 4.9 & 5.2 & 62 & 30 & 61 & 18 & - & - & 14.3 & 1 \\
\hline 13 & 1996 & 3.5 & $\mathrm{M}$ & 16 & RFS & 3 & 10 & 1.9 & 3.9 & 52 & 22 & 64 & 46 & - & - & 11.5 & $1^{*}$ \\
\hline 14 & 1997 & 10.5 & $\mathrm{M}$ & 30 & RPA & 3 & 16 & 6 & 6 & 75 & 45 & 106 & 51 & - & - & NF & $0^{*}$ \\
\hline 15 & 1997 & 1.1 & $\mathrm{~F}$ & 8.3 & RFS & 3 & 8 & 4.7 & 3.2 & 44 & 18 & 68 & 78 & - & - & 10.6 & 1 \\
\hline 16 & 1997 & 0.2 & $\mathrm{M}$ & 5.9 & LFS & 0 & 7 & 7 & 3.6 & 45 & 22 & 43 & 28 & - & - & 10.2 & 0 \\
\hline 17 & 1998 & 0.3 & $\mathrm{~F}$ & 5.5 & LFS & 4 & 18 & 15.6 & 5.4 & 36 & 9 & 66 & 158 & $6 \ddagger$ & 10 & 9.6 & $1^{*}$ \\
\hline 18 & 1999 & 10.8 & $\mathrm{M}$ & 38 & RFS & 2 & 8 & 1.1 & 4.5 & 68 & 31 & 50 & 30 & - & - & 9.0 & 1 \\
\hline 19 & 2000 & 2.0 & $\mathrm{M}$ & 11.6 & RFS & 3 & 22 & 7.1 & 4.9 & 65 & 32 & 56 & 24 & - & - & $\mathrm{NF}$ & $1^{*}$ \\
\hline 20 & 2001 & 0.5 & $\mathrm{~F}$ & 5.6 & RFS & 3 & 15 & 4.7 & 3.1 & 76 & 30 & 89 & 71 & - & 5 & 6.6 & $1^{*}$ \\
\hline 21 & 2004 & 0.3 & $\mathrm{~F}$ & 5 & RFS & 2 & 19 & 16.7 & 5 & 37 & 7 & 38 & 230 & $10 \S$ & 11 & 5.0 & 1 \\
\hline 22 & 2004 & 0.2 & $\mathrm{M}$ & 4 & RFS & 4 & 15 & 11.7 & 4.1 & 19 & 7 & 66 & 225 & $12 \S$ & 12 & 4.6 & 2 \\
\hline 23 & 2005 & 0.3 & $\mathrm{~F}$ & 5 & RFS & 3 & 25 & 10.9 & 4.4 & 20 & 12 & 55 & 92 & $6 \ddagger$ & - & 2.6 & 2 \\
\hline 24 & 2005 & 6.2 & $\mathrm{M}$ & 24 & RFS & 1 & 8 & 4.9 & 5.1 & 50 & 25 & 45 & 13 & - & - & 2.9 & 0 \\
\hline 25 & 2007 & 0.6 & $\mathrm{M}$ & 8 & NFS & 1 & 25 & 10.8 & 4.3 & 19 & 9 & 51 & 71 & $4 \ddagger$ & 6 & 1.4 & 0 \\
\hline 26 & 2007 & 1.3 & $\mathrm{~F}$ & 8 & NFS & 3 & 7 & 1.6 & 3 & 48 & 24 & 76 & 34 & - & - & 0.5 & $2^{*}$ \\
\hline 27 & 2010 & 0.1 & $\mathrm{~F}$ & 3.6 & NFS & 1 & 15 & 9.5 & 3.5 & 30 & 14 & 66 & 55 & - & 7 & $\mathrm{NF}$ & 1 \\
\hline
\end{tabular}

$L C A$, Left coronary artery; Preop, preoperative; $M V I$, mitral valve incompetence; $L V E D P$, left ventricular end-diastolic pressure; $L V E D D$, left ventricular end-diastolic diameter; $L V E F$, left ventricular ejection fraction; $L V F S$, left ventricular fraction of shortening; $L V A D$, left ventricular assist device; $D S C$, delayed sternal closure; $D H Z B$, Deutsches Herzzentrum Berlin; postop, postoperative; $F$, female; $R F S$, right-facing sinus; $M$, male, $N F$, no follow-up at Deutsches Herzzentrum Berlin, $M P A$, main pulmonary artery; $N F S$, nonfacing sinus; $R P A$, right pulmonary artery; $L F S$, left-facing sinus. *Mitral valve repair. $\dagger$ Extracorporeal membrane oxygenation. $\ddagger$ Left ventricular assist device, centrifugal pump. $\S$ Left ventricular assist device, Berlin Heart Excor(Berlin Heart AG, Berlin, Germany).

moderate (grade II) in 3, severe (grade III) in 10, and severest (grade IV) in 3.

\section{Early Results}

There were no in-hospital deaths. Ten patients required inotropic support for 24 to 36 hours after the operation. The postoperative course was uneventful in 12 cases, and these patients were extubated 6 to 18 hours after the operation. For the remaining 15 patients with an open chest, the sternum was closed 1 to 7 days after coronary reimplantation or LVAD explantation. All patients showed significant improvement after coronary reimplantation. Color Doppler echocardiograms before discharge and coronary angiograms ( 2 patients) indicated that the reimplanted left coronary artery was patent in all 27 patients.

Preoperative severe MVI decreased or disappeared in all 9 patients with mitral valve repair (grade II in 2 patients, grade I in 6, and no MVI in 1) at discharge (Figure 1, A). No mitral valve repair was performed in 4 patients with preoperative MVI grades III ( 3 patients) and IV (1 patient). Postoperative MVI in these patients was diminished to grade II in 3 patients and grade I in 1 (Figure 1,B).
In the 6 patients supported with LVADs, the left ventricular function improved after 4 to 12 days, leading to successful LVAD weaning and explantation and subsequent discharge from hospital. There was no difference between infants with and without LVAD support in the incidence of severe MVI (3 vs 4 patients), incidence of preoperative ventilation ( 2 vs 3 patients), age (3.8 vs 3.7 months), weight (5.3 vs $5.5 \mathrm{~kg}$ ), or aortic clamp time (60 vs 57 minutes); however, infants with LVAD support preoperatively showed significantly lower LVEF and LVFS and larger cardiothoracic ratio and especially statistically larger LVEDD and higher left ventricular end-diastolic pressure than infants without LVAD support, as we reported previously. ${ }^{14}$ One infant in the LVAD group and 2 in the non-LVAD group underwent mitral valve reconstruction.

\section{Follow-up}

After 13.2 years (range, $0.2-18.4$ years), all patients are alive. Follow-up in our outpatient department is complete for 22 patients after 11.5 years (range, 0.5-17.5 years). One 1-month-old infant was operated on recently (May 2010). Four patients are being seen regularly by local cardiologists in other cities in Germany. 


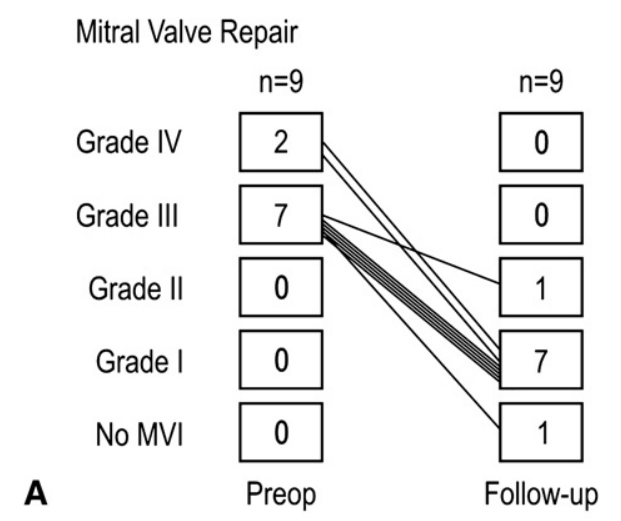

No Mitral Valve Repair

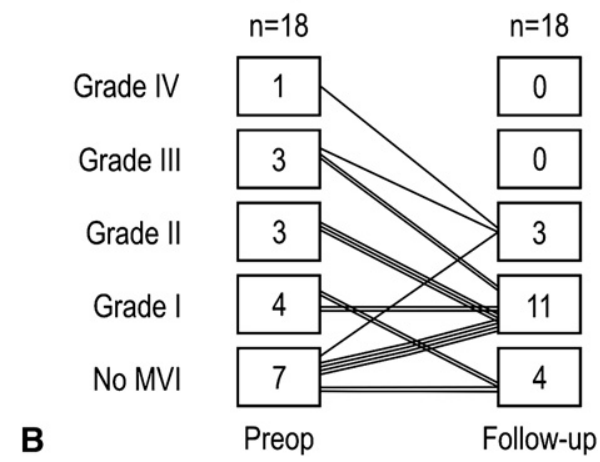

FIGURE 1. Mitral valve incompetence (MVI) before (Preop) and after (Follow-up) repair of anomalous left coronary artery from the pulmonary artery. A, Patients with mitral valve repair, B, Patients with no mitral valve repair.

Two small children $(<2$ years $)$ are at home with their parents. Three children are in kindergarten, 4 are attending primary school, and 9 are in high school. Nine adult patients are working.

All patients are free of symptoms, and all but 3 have no restriction during physical activity. One 16-year-old female patient (LVAD group, patient 11; Table 1) has restricted fine motor skills. Another 16-year-old female patient (nonLVAD group, patient 8; Table 1) has limited mental skills and is attending a special school. Both girls had no documented cardiopulmonary resuscitation, cardiac arrest, or low-flow episodes during the hospital stay or before the operation. Eight patients regularly take part in sports activities: 3 play soccer, 1 plays basketball, 3 enjoy horse riding, and 2 go swimming and bicycling.

Standard and Holter electrocardiography revealed no arrhythmias in 22 investigated patients.

Antegrade flow in the reimplanted coronary artery was documented by echocardiography in all patients, by magnetic resonance imaging (MRI) in 21 and during cardiac catheterization in 10, with the latter group including 6 patients who did not undergo MRI investigation.

During follow-up MRI (1.5-Tmagnetic resonance scanner, Achieva R 2.6; Philips Medical Systems, Best, The
Netherlands), which was performed 0.6 to 17.5 years after ALCAPA correction, myocardial perfusion deficit was observed at rest in 6 patients and during dobutamine stress test in an additional 1 patient. No wall motion abnormalities were observed in 7 patients; there were hypokinesia and akinesia in an additional 7 patients each and dyskinesia in 5 patients. Left ventricular wall scar tissue was present in 12 of 21 investigated patients (57\%): 7 had endocardial scars and 5 had transmural scars. In 2 patients (patients 21 and 22; Table 1) in whom virtually no left ventricular function was present after ALCAPA repair, the Berlin Heart Excor VAD was implanted with apical cannulation. Both patients recovered, and the LVAD was explanted. In these 2 patients, follow-up MRI showed a small apical left ventricular scar and apical akinesia at the cannulation site.

Echocardiography (VIVID 7; GE Medical Systems, Milwaukee, Wis) showed normalization of global left ventricular function and geometry in long-term follow-up. There were no statistically significant differences for left ventricular function or geometry between patients who needed postoperative mechanical circulatory support and those who did not. ${ }^{14}$ Patients with MRI-documented left ventricular wall scar tissue had similar global left ventricular systolic function to that of patients with no left ventricular wall scar (LVEF $59 \% \pm 8 \%$ vs $64 \% \pm 6 \%, P=.17$ ). Only 3 patients $(14 \%)$ showed no regional wall motion abnormalities at all, and 19 patients $(86 \%)$ showed wall motion abnormalities in 1 to 6 left ventricular areas.

Twenty patients $(95 \%)$ showed no signs of supravalvular pulmonary stenosis (peak velocity $1.5 \pm 0.6 \mathrm{~m} / \mathrm{s}$ ) and 1 patient $(5 \%)$ displayed a moderate supravalvular stenosis of the main pulmonary artery (peak velocity $4.0 \mathrm{~m} / \mathrm{s}$ ). Mild main pulmonary artery stenosis (systolic gradient 10-20 $\mathrm{mm} \mathrm{Hg}$ ) was present in 5 patients $(24 \%)$. There was no sign of aortic valve incompetence in any patient at longterm follow-up.

\section{Mitral Valve Incompetence}

Nine patients had undergone mitral annuloplasty at initial corrective surgery. At long-term follow-up examination, 7 patients $(78 \%)$ exhibited only grade I MVI, and 1 patient each $(11 \%)$ had no or grade II MVI (Figure $1, A)$. Among the 18 patients in whom no mitral valve reconstruction was performed during ALCAPA repair, MVI was absent in 4 patients $(22 \%)$, grade I was present in 10 patients $(56 \%)$, and grade II was observed in 3 patients $(17 \%)$. Five of the 18 patients without mitral valve reconstruction $(28 \%)$ had displayed no MVI before ALCAPA repair but showed an increase in MVI to grade I or II at long-term follow-up (Figure 1, B).

\section{DISCUSSION}

ALCAPA is a rare congenital anomaly that often causes myocardial ischemia and infarction within the first few 
weeks or months after birth, subsequently leading to left ventricular dysfunction, MVI, and congestive heart failure. Even with medical treatment, mortality among infants with signs of left ventricular ischemia and infarction approaches $85 \%$ during the first year of life. ${ }^{15}$ Infants with ALCAPA are subject to acute myocardial ischemia because of lack of well-developed collaterals, unlike in older children, and are at high risk of death without surgical intervention. Thus surgical repair appears to provide the only viable hope for extended survival.

Direct reimplantation of the anomalous left coronary artery to the aorta was possible in all but 1 of our pediatric patients, irrespective of origin of the left coronary. Additional maneuvers to elongate the left coronary artery were necessary in only 1 case. No patients with ALCAPA referred to our institution required heart transplant or were rejected for surgery.

There have been several reports of surgical treatment of ALCAPA without deaths, mostly in older children. ${ }^{4,16-18}$ In all but 1 of these series ${ }^{16}$ no detailed quantitative data regarding preoperative left ventricular function and MVI were given. Backer and colleagues ${ }^{4}$ reported successful reimplantation of the left coronary artery into the aorta in 16 patients without any deaths. In their patients, no LVADs were used. It has been speculated that their patients happened to have more hibernating and less infarcted myocardium than those in other reported series because of patient selection. ${ }^{19}$

Severity of left ventricular dysfunction plays a major role in postoperative mortality, especially when temporary LVAD support is not used.

Schwartz and associates ${ }^{20}$ found no correlation between preoperative LVFS and mortality; however, they used LVADs in 7 patients, with 5 survivors. In the presence of significantly depressed preoperative left ventricular function (preoperative LVEF $\leq 37 \%$, LVFS $\leq 15 \%$, and left ventricular end-diastolic pressure $\geq 18 \mathrm{~mm} \mathrm{Hg}$ in infants) combined with LVEDD of more than $4.0 \mathrm{~cm}$ (LVEDD $z$ score $>10.6$ ), the likelihood of postoperative temporary LVAD use in infants was $100 \%$ in our series (Table 1). ${ }^{14}$

We use left univentricular support with a closed-system centrifugal pump or pneumatic assist device instead of extracorporeal membrane oxygenation, because usually there is an isolated left ventricular problem not involving pulmonary gas exchange or right ventricular function. ${ }^{21}$ Temporary centrifugal pump devices can be used for only as long as 2 weeks, by which time restoration of left ventricular function after correction of ALCAPA is usually expected.

In our study group, we had no deaths and therefore were not able to detect risk factors for death. Without LVAD support, however, mortality might have been as high as $26 \%$. All our patients who required LVAD support after ALCAPA repair were infants. There was no need for postoperative LVAD in the 12 older children, except for 1 with an iatro- genic supravalvular pulmonary stenosis as described previously. Contrary to Ben Ali and colleagues, ${ }^{22}$ we did not identify implantation of LVAD as a risk factor for inhospital mortality. Nevertheless, there are patients, even infants, with extensive irreversible left ventricular myocardial damage despite establishment of a dual coronary system, although until now we have not faced such a situation. In such cases, cardiac transplant is the only option. ${ }^{23}$

Mitral valve surgery in patients with ALCAPA is still a controversial issue. Some authors do not recommend mitral valve surgery during coronary reimplantation, claiming that MVI improves or completely disappears later, particularly in infants, albeit without completely going away.,5,19,24-27 Contrarily, Isomatsu and coworkers ${ }^{28}$ recommend that simultaneous mitral annuloplasty be performed at the time of operation in all patients with ALCAPA and mild to severe MVI.

Lambert and associates ${ }^{2}$ observed persistence of severe MVI (grade III and IV) in 6\% of their patients during follow-up. Caspi and colleagues ${ }^{5}$ observed postoperative regression of MVI to mild in $34 \%$ of the 23 patients in whom coronary transfer was performed without addressing the mitral valve, including 20 patients with severe preoperative MVI. Most of their patients were infants. Cochrane and colleagues ${ }^{29}$ observed minimal or no improvement of MVI in $44 \%$ of their 16 patients with a follow-up as long as 18 years.

Azakie and associates ${ }^{24}$ showed that improvements in MVI lagged behind normalization of ejection fraction and left ventricular dilatation. In the series of Schwartz and coworkers ${ }^{20}$ the degree of MVI during follow-up improved in $62 \%$ of patients and remained unchanged in $38 \%$. According to Caspi and colleagues, ${ }^{5}$ in older children repair of MVI at the time of coronary transfer may be warranted because, unlike in infants, the MVI is caused by irreversible myocardial damage or papillary muscle infarction. The median age of our 9 patients who underwent mitral valve repair was 2 years (range, 6.6 months- 10.5 years), and only 3 patients were infants (patients 4, 17, and 20; Table 1).

Severity of MVI has also been described as a risk factor for mortality, ${ }^{20}$ and that might be why LVAD support was needed by 3 of our infants in whom severe MVI was not corrected. Mild increase in MVI was observed only in patients in whom mitral valve reconstruction was not performed.

There are several, often combined, causes of MVI in patients with ALCAPA: infarction; scarring and calcification of papillary muscles (mostly the anterior papillary muscle is involved); endocardial fibroelastosis involving chordae tendineae, papillary muscles, and mitral leaflets; dilatation of the mitral valve ring with displacement of the papillary muscles; and left ventricular free wall dyskinesia. ${ }^{30}$ In older children, severe MVI can be the only manifestation of ALCAPA. ${ }^{31}$ Interestingly, in some of our patients with very dilated left ventricles, minimal or no MVI was observed (patients 1, 6, 11, and 16; Table 1). 
The decision to correct MVI should be flexible and based on its underlying causes. Simultaneous correction of severe MVI, particularly in older children with ALCAPA, appears to be a logical means of supporting cardiac output during the critical immediate postoperative period. Persistent severe MVI can be a cause of malignant arrhythmias and sudden death, even after successful establishment of 2 coronary systems. ${ }^{32}$

We agree with Isomatsu and associates ${ }^{28}$ that the added ischemic time, usually 20 minutes (10 minutes in our series) necessary for mitral valve repair does not have a deleterious effect on the myocardium as has been suggested by some authors. ${ }^{3,33}$ No patient with mitral valve repair in our series exhibited severe hemodynamic instability after the operation or needed an LVAD, and all were extubated 3 hours to 13 days after the operation. Huddleston and coworkers $^{19}$ showed that residual coronary obstruction must be excluded as a reason for increasing MVI after coronary reimplantation. In all patients with residual MVI, open coronary anastomosis and improved global LV function were documented by cardiac catheterization or MRI and echocardiography during follow-up.

Even in the absence of coronary occlusion and with normalization of left ventricular function, some patients need later mitral valve surgery, including valve replacement. ${ }^{24,29,32-34}$ In our institution, we prefer to correct severe MVI during ALCAPA repair, and maybe because of that policy no patient needed late reoperation for MVI. On the basis of our experience, we recommend mitral valve repair only for patients with severe or severest MVI, especially older children. We believe that decrease of MVI cannot be expected without addressing the mitral valve during ALCAPA correction in older children with severe MVI, even with almost normal left ventricular function, and only in patients with mild or moderate MVI can improvement of valve function be expected without mitral valve repair.

Short-term follow-up of our first 11 patients with ALCAPA revealed favorable potential for myocardial recovery within 1 year after direct aortic reimplantation of the left coronary artery, with improvement faster in infants than in older children. ${ }^{35}$ This finding supports the hypothesis that in infants the potential for myocardial recovery is higher because they have more hibernating myocardium and less infarcted myocardium than do older children. ${ }^{36}$

Despite these early improvements in global left ventricular function, late MRI findings in our patients correspond with those of other authors who showed that, despite restoration of global LV function and open coronary anastomosis, perfusion deficits are observed in many patients with incomplete redistribution involving the anterior septal and anterior lateral segments. ${ }^{2,37,38}$ The reduced left ventricular regional function late after successful surgical correction of ALCAPA is thus related to left ventricular wall scar tissue and myocardial perfusion deficits and can potentially serve as a substrate for cardiac arrhythmias later in life.

\section{CONCLUSIONS}

Despite the absence of early and late deaths, the longterm prognosis for patients who undergo reimplantation of the left coronary artery into the aorta is not clear. Improvement of global left ventricular function (LVEF and LVFS) is overestimated and may not reflect residual myocardial damage, as seen by the presence of scars and perfusion deficits in the left ventricular myocardium. This underlines the need for lifelong follow-up of all patients after successful correction of ALCAPA, including regular MRI studies to detect abnormal changes in perfusion and scar areas in the left ventricle.

We thank Anne Gale, medical editor, for assistance with this article. We also appreciate the assistance of Astrid Benhennour, Julia Stein, Karla Weber, and Helge Haselbach.

\section{References}

1. Kakou Guikahue M, Sidi D, Kachaner J, Villain E, Cohen L, Piechaud JF, et al. Anomalous left coronary artery arising from the pulmonary artery in infancy: is early operation better? Br Heart J. 1988;60:522-6.

2. Lambert V, Touchot A, Losay J, Piot JD, Henglein D, Serraf A, et al. Midterm results after surgical repair of the anomalous origin of the coronary artery. Circulation. 1996;94(9 Suppl):II38-43.

3. Dodge-Khatami A, Mavroudis C, Backer CL. Anomalous origin of the left coronary artery from the pulmonary artery: collective review of surgical therapy. Ann Thorac Surg. 2002;74:946-55.

4. Backer CL, Hillman N, Dodge-Khatami A, Mavroudis C. Anomalous origin of the left coronary artery from the pulmonary artery: successful surgical strategy without assist devices. Semin Thorac Cardiovasc Surg Pediatr Card Surg Аnnu. 2000;3:165-72.

5. Caspi J, Pettitt TW, Sperrazza C, Mulder T, Stopa A. Reimplantation of anomalous left coronary artery from the pulmonary artery without mitral valve repair. Ann Thorac Surg. 2007;84:619-23.

6. Alexi-Meskishvili V, Hetzer R, Weng Y, Lange PE, Jin Z, Berger F, et al. Anomalous origin of the left coronary artery from the pulmonary artery. Early results with direct aortic reimplantation. J Thorac Cardiovasc Surg. 1994;108:354-62.

7. Alexi-Meskishvili V, Hetzer R, Weng Y, Loebe M, Lange PE, Ishino K. Successful extracorporeal circulatory support after aortic reimplantation of anomalous left coronary artery. Eur J Cardiothorac Surg. 1994;8:533-6.

8. Hübler M, Koster A, Redlin M, Boettcher W, Stiller B, Nürnberg J, et al. Repair of ALCAPA in a 4-kg patient followed by successful weaning and "off-pump" explantation of an apical venting LVAD. J Card Surg. 2005;20:261-3.

9. Dodge-Khatami A, Mavroudis C, Backer CL. Congenital heart surgery nomenclature and database project: anomalies of the coronary arteries. Ann Thorac Surg. 2000;69(4 Suppl):S270-97.

10. Smith A, Arnold A, Anderson RH, Wilkinson JL, Qureshi SA, Gerlis LM, et al. Anomalous origin of the left coronary artery from the pulmonary trunk. Anatomic findings in relation to pathophysiology and surgical repair. J Thorac Cardiovasc Surg. 1989;98:16-24.

11. Stiles QR. Surgery for anomalous origin of the left coronary artery from the pulmonary artery. In: Tucker BL, Lindesmith GG, eds. Congenital heart disease. New York: Grune \& Stratton; 1979. p. 285-93.

12. Hetzer R, Alexi-Meskishvili V, Weng Y, Hübler M, Potapov E, Drews T, et al Mechanical cardiac support in the young with the Berlin Heart EXCOR pulsatile ventricular assist device: 15 years' experience. Semin Thorac Cardiovasc Surg Pediatr Card Surg Annu. 2006;9:99-108.

13. Buck T, Pflicht B, Erbel R. [Current recommendations on echocardiographic evaluation of the severity of mitral regurgitation: standardization and practical application using a scoring system]. Aktuelle Empfehlungen zur echokardiographischen Schweregradbeurteilung der Mitralklappeninsuffizienz: Standardisierung und praktische Anwendung mittels eines Scoringsystems. Herz. 2006;31:30-7. German. 
14. Nasseri BA, Alexi-Meskishvili V, Nordmeyer S, Weng YG, Böttcher W, Hübler M, et al. Predictors for the use of left ventricular assist devices in infants with anomalous left coronary artery from the pulmonary artery. Ann Thorac Surg. 2010;90:580-7.

15. Keith JD. Diseases of coronary arteries and aorta. In: Keith JD, Rowe RD, Vlad P, eds. Heart disease in infancy and childhood. New York: Macmillan; 1978. p. 1014-9.

16. Moraes F, Lincoln C. Anomalous origin of left coronary artery. Evolution of surgical treatment. Eur J Cardiothorac Surg. 1996;10:603-8.

17. Neirotti R, Nijveld A, Ithuralde M, Quaglio M, Seara C, Lubbers L, et al. Anomalous origin of the left coronary artery from the pulmonary artery: repair by aortic reimplantation. Eur J Cardiothorac Surg. 1991;5:368-72.

18. Turley K, Szarnicki RJ, Flachsbart KD, Richter RC, Popper RW, Tarnoff H. Aortic implantation is possible in all cases of anomalous origin of the left coronary artery from the pulmonary artery. Ann Thorac Surg. 1995;60:84-9.

19. Huddleston CB, Balzer DT, Mendeloff EN. Repair of anomalous left main pulmonary artery arising from the pulmonary artery in infants: long-term impact on mitral valve. Ann Thorac Surg. 2001;71:1985-8; discussion 1988-9.

20. Schwartz ML, Jonas RA, Colan SD. Anomalous origin of left coronary artery from pulmonary artery: recovery of left ventricular function after dual coronary repair. J Am Coll Cardiol. 1997;30:547-53.

21. Karl TR, Horton SB, Brizard C. Postoperative support with centrifugal pump ventricular assist device (VAD). Semin Thorac Cardiovasc Surg Pediatr Card Surg Annu. 2006;9:83-91.

22. Ben Ali W, Metton O, Roubertie F, Pouard P, Sidi D, Raisky O, et al. Anomalous origin of the left coronary artery from the pulmonary artery: late results with special attention to the mitral valve. Eur J Cardiothorac Surg. 2009;36:244-9.

23. Browne LP, Kearney D, Taylor MD, Chung T, Slesnick TC, Nutting AC, et al. ALCAPA: the role of myocardial viability studies in determining prognosis. $\mathrm{Pe}$ diatr Radiol. 2010;40:163-7.

24. Azakie A, Russell JL, McCrindle BW, Van Arsdell GS, Benson LN, Coles JG, et al. Anatomic repair of anomalous left coronary artery from the pulmonary artery by aortic reimplantation: early survival, patterns of ventricular recovery and late outcome. Ann Thorac Surg. 2003;75:1535-41.

25. Barth MJ, Allen BS, Gulecyuz M, Chiemmongkoltip P, Cuenao B, Ilbawi MN. Experience with an alternative technique for the management of anomalous left coronary artery from the pulmonary artery. Ann Thorac Surg. 2003;76:1429-34.

26. Laks H, Ardehali A, Grant PW, Allada V. Aortic implantation of anomalous left coronary artery. An improved surgical approach. J Thorac Cardiovasc Surg. 1995;109:519-23.
27. Vouhé PR, Baillot-Vernant F, Trinquet F, Sidi D, de Geeter B, Khoury W, et al. Anomalous left coronary artery from the pulmonary artery in infants. Which operation? When? J Thorac Cardiovasc Surg. 1987;94:192-9.

28. Isomatsu Y, Imai Y, Shin'oka T, Aoki M, Iwata Y. Surgical intervention for anomalous origin of the left coronary artery from the pulmonary artery: the Tokyo experience. J Thorac Cardiovasc Surg. 2001;121:792-7.

29. Cochrane AD, Coleman DM, Davis AM, Brizard CP, Wolfe R, Karl TR. Excellent long-term functional outcome after an operation for anomalous left coronary artery from the pulmonary artery. J Thorac Cardiovasc Surg. 1999; 117:332-42.

30. Wesselhoeft H, Fawcett JS, Johnson AL. Anomalous origin of the left coronary artery from the pulmonary trunk: its clinical spectrum, pathology and pathophysiology, based on a review of 140 cases with seven further cases. Circulation. 1968;38:403-25.

31. Dahle G, Fiane AE, Lindberg HL. ALCAPA, a possible reason for mitral insufficiency and heart failure in young patients. Scand Cardiovasc J. 2007;41:51-8.

32. Lange R, Vogt M, Hörer J, Cleiuziou J, Menzel A, Holper K, et al. Long-term results of repair of anomalous origin of the left coronary artery from the pulmonary artery. Ann Thorac Surg. 2007;83:1463-71.

33. Michielon G, Di Carlo D, Brancaccio G, Guccione P, Mazzera E, Toscano A, et al. Anomalous coronary artery origin from the pulmonary artery: correlation between surgical timing and left ventricular function recovery. Ann Thorac Surg. 2003;76:581-8.

34. Vouhé PR, Tamisier D, Sidi D, Vernant F, Mauriat P, Pouard P, et al. Anomalous left coronary artery from the pulmonary artery: results of isolated aortic reimplantation. Ann Thorac Surg. 1992;54:621-7.

35. Jin Z, Berger F, Uhleman F, Schröder C, Hetzer R, Alexi-Meskishvili V, et al. Improvement in left ventricular dysfunction after aortic reimplantation in 11 consecutive pediatric patients with anomalous origin of the left coronary artery from the pulmonary artery: Early results of serial echocardiographic followup. Eur Heart J. 1994;15:1044-9.

36. Shivalkar B, Borgers M, Daenen W, Gewillig M, Flameng W. ALCAPA syndrome: an example of chronic myocardial hypoperfusion? J Am Coll Cardiol. 1994;23:772-8

37. Berdjis F, Takahashi M, Wells WJ, Stiles QR, Lindesmith GG. Anomalous left coronary artery from the pulmonary artery. Significance of intracoronary collaterals. J Thorac Cardiovasc Surg. 1994;108:17-20.

38. Seguchi M, Nakanishi T, Nakazawa M, Doi S, Momma K, Takao A, et al. Myocardial perfusion after aortic implantation for anomalous origin of the left coronary artery from the pulmonary artery. Eur Heart J. 1990;11:213-8. 